\title{
Bases Constitucionales del Principio de Transparencia
}

\section{Resumen}

El autor analiza el principio de transparencia, desde sus primeros antecedentes en el ordenamiento constitucional chileno hasta su consagración plena en la Constitución de 1980, con la reforma de 2005. Se ilustra con referencias al derecho comparado y con la reciente jurisprudencia del Tribunal Constitucional.

\section{Palabras clave}

Transparencia, publicidad, jurisprudencia

\section{Primeros Textos Constitucionales Chilenos}

Los antecedentes remotos del principio de transparencia en el Derecho chileno podemos encontrarlos en los primeros textos constitucionales dictados durante la primera mitad del siglo XIX.

Incluso, ya el Plan de Hacienda y Administración Pública, de 1817, se refiere a la publicidad de las cuentas, a través del Tribunal de Cuentas. ${ }^{1}$

Profesor de Derecho Constitucional

Director

Departamento de Derecho Público Universidad de Chile Ministro del Tribunal Constitucional

\footnotetext{
El Tribunal de Cuentas debía revisar todas las rentas y derechos pertenecientes al Estado. Así, dicho tribunal debía tomar razón "de toda comisión que perciba caudales o intereses de la Hacienda pública" (art. 94). Todo presupuesto de gastos de hacienda debía ser revisado, a objeto de representar "cualquier exceso, dispendio o desarreglo que notaren respecto de lo propuesto, y su consiguiente ejecución" (art. 95). En tal sentido, "debe siempre este tribunal entender que toda cuenta y presupuesto no se le pasa para el simple examen del guarismo, sino para conocer sobre la veracidad y justicia de cada partida, a efecto de que jamás se dispendien los fondos públicos" (art. 95). De modo que "su objeto ha de ser evitar los fraudes que se maquinan contra éstos por el interés individual, y el velar principalmente que ninguno omita o retarde las debidas cuentas" (art. 95).
} 
Por su parte, la Constitución Política de 1822 alude a la publicidad de la ley y de la Constitución ${ }^{3}$ como asimismo a la existencia de un Registro Público de Personas Privadas de Libertad. ${ }^{4}$

A su vez, la Constitución moralista de 1823 consagra el principio de publicidad de las actuaciones penales. ${ }^{5}$

Por su lado, la Constitución liberal de 1828 establece por primera vez la rendición anual de cuentas. ${ }^{6}$

La Constitución de 1833, además de reiterar el principio básico de la publicidad de las leyes y de la Constitución, prevé el secreto en materia de relaciones internacionales. ${ }^{7}$

Por su parte, en el siglo XX, la Constitución Política de 1925 establece reglas muy generales, en particular relativas a la publicidad de los procesos electorales ${ }^{8}$, de las actuaciones de los órganos colegiados e igualmente ciertas garantías del proceso penal.

\section{La Constitución de 1980}

El texto primitivo de la Constitución de $1980^{10}$ establecía breves referencias al principio de publicidad.

En primer lugar, se alude a la existencia de un "istema electoral público". ${ }^{11}$

Del mismo modo, se tutelaba la "vida pública" 12 , lo que se eliminó en la reforma de 2005.

Por su lado, la contabilidad de los partidos políticos también debe ser pública. ${ }^{13}$

\footnotetext{
El proyecto de ley aprobado por ambas Cámaras pasará al Director del Estado, "para que lo suscriba y publique" (art. 55 de la Constitución de 1822).

El Poder Ejecutivo debe determinar el modo "como haya de publicarse" la Constitución (art. 248).

4 El alcaide "llevará un libro en que se asiente el día, hora y motivo de la prisión y nombre del juez que la decretó" (art. 209).

5 El artículo 136 establece que "en toda demanda se permite a las partes el acceso a sus jueces por juicios y procesos verbales".

6 Son deberes básicos del Poder Ejecutivo "dar anualmente, al Congreso, luego que abra sus sesiones, razón del Estado de la Nación en todos los ramos del Gobierno" (art. $84 \mathrm{~N}^{\circ} 4$ ).

7 "Las discusiones y deliberaciones sobre estos objetos serán secretas, si asi lo exige el Presidente de la República" (art. 82 № 19). Sobre la Constitución de 1833 vid. CARRASCO A., MANUEL, "Comentarios sobre la Constitución de 1833”, Santiago, 1958. Sobre la Constitución de 1833 vid. HUNEEUS Z. JORGE, La Constitución ante el Congreso, 2 vols., 1879. También sobre la carta de 1833 vid. LASTARRIA JOSÉ V., La Constitución Comentada, 1856; y al final del período ROLDÁN ALCIBÍADES, Elementos de Derecho Constitucional, 1924.

Se establece que los registros electorales "serán públicos" (art. 7).

9 Las dos ramas del Congreso "reunidas en sesión pública" tomarán conocimiento del escrutinio y procederán a proclamar al Presidente de la República (art. 64) Por su parte, respecto de la Constitución de 1925 vid. GUERRA V. JOSÉ G., La Constitución de 1925, 1929; BERNASCHINA G. MARIO, Manual de Derecho Constitucional, 1951; y SILVA B. ALEJANDRO, Tratado de Derecho Constitucional, 3 vols., 1963.

10 Vid. NAVARRO B., ENRIQUE, “20 años de la Constitución Chilena. 1981-2001”, Santiago, 2001.

11 Artículo 18 de la Constitución Política.

12 Artículo $19 \mathrm{~N}^{\circ} 4$ de la Constitución Política.

13 Artículo $19 \mathrm{~N}^{\circ} 15$ de la Constitución Política.
} 
En materia de relaciones internacionales se reitera la disposición según la cual "las discusiones y deliberaciones sobre estos objetos serán secretas si el Presidente de la República asi lo exigiere". ${ }^{14}$

La publicación de la ley, la que deberá efectuarse "dentro de los cinco días hábiles siguientes a la fecha en que quede totalmente tramitado el decreto promulgatorio". 15

Por último, el texto original de la Carta de 1980 expresaba que los acuerdos u opiniones del Consejo de Seguridad Nacional serían "públicos o privados", según lo determinara para cada caso dicho órgano. ${ }^{16}$

\section{Referencia al Derecho Constitucional Comparado}

Las clásicas Constituciones europeas no es mucho lo que se refieren a este tópico, que no sea en relación a la publicidad de las actuaciones de los órganos del Estado y, en particular, de la ley.

En efecto, la Carta Fundamental italiana de 1947 establece que las sesiones del Parlamento serán públicas, sin perjuicio de que pueda acordarse reunirse en sesión secreta. ${ }^{17}$ El Reglamentos de las Cámaras debe especificar la forma de publicidad de los trabajos de sus comisiones. ${ }^{18}$ Por último, se alude a la obligación de publicación de las leyes ${ }^{19}$, de los decretos con fuerza de ley ${ }^{20} \mathrm{y}$ de los reglamentos regionales. ${ }^{21}$

La Ley Fundamental alemana de 1949, además de reiterar normas similares en cuanto a que las sesiones del Bundestag son públicas ${ }^{22}$, y la publicidad de las disposiciones jurídicas ${ }^{23}$, agrega que los partidos políticos deben "dar cuenta públicamente de la procedencia y uso de sus recursos, asi como de su patrimonio"." ${ }^{4}$

La Constitución francesa de 1958 indica que las sesiones de las dos Cámaras serán públicas y que el acta integral de los debates se publicará en el boletín oficial. Del mismo modo, cada Cámara podrá reunirse en sesión secreta a petición del Primer Ministro o una décima parte de sus miembros. ${ }^{25}$

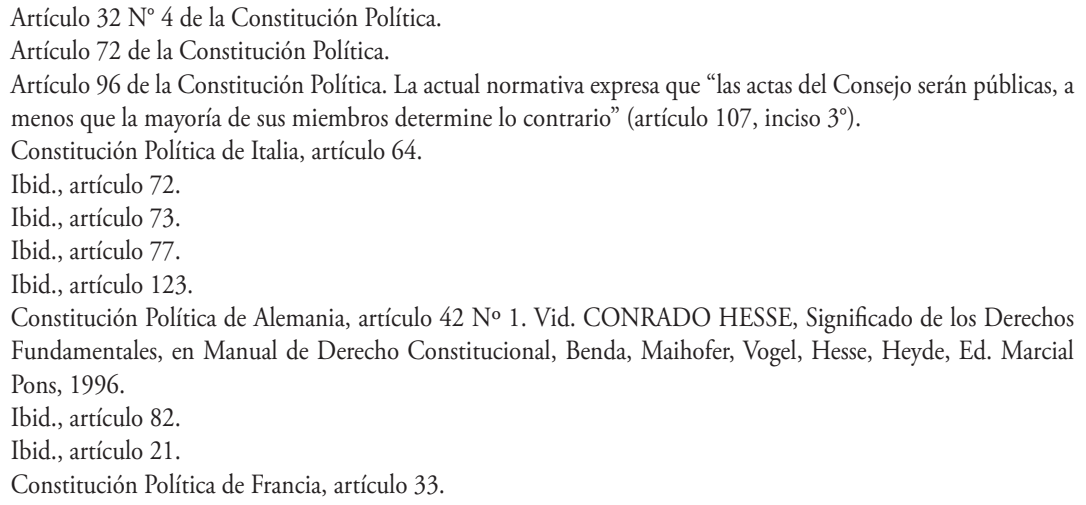


Por último la Constitución española de 1978 alude a la publicidad de las normas ${ }^{26}$, de las sesiones de las Cámaras $^{27}$ y de las actuaciones judiciales ${ }^{28}$, a la vez que preceptúa que la ley deberá regular "el acceso de los ciudadanos a los archivos y registros administrativos, salvo en lo que afecte a la seguridad y defensa del Estado, la averiguación de los delitos y la intimidad de las personas". ${ }^{2}$

Cabe tener presente que la Constitución de los Estados Unidos de América expresa que "cada una de las Cámaras llevará un diario de sus diligencias, el cual será publicado a intervalos regulares, salvo las partes que a juicio de aquéllas deban permanecer en secreto". ${ }^{30}$

Tratándose de las Constituciones iberoamericanas la situación es disímil de acuerdo a la época de las mismas. Algunas establecen principios muy generales acerca de la publicidad y transparencia.

Así, la de Paraguay de 1992 sólo se refiere a la publicación de las leyes ${ }^{31}$ y al carácter público de los juicios. ${ }^{32} \mathrm{O}$, como en el caso de Puerto Rico, que las sesiones serán públicas. ${ }^{33} \mathrm{O}$ la publicidad de las leyes, como expresan las de El Salvador de $1983^{34}$, Honduras de $1982^{35}$ o Nicaragua, de $1986 .^{36}$

En otros casos, existen regulaciones referidas a los partidos políticos. Por ejemplo, la Constitución argentina alude a la obligación de los partidos políticos de dar publicidad acerca del origen y destino de sus fondos y patrimonio. ${ }^{37}$ En Uruguay, la Carta de 1967, establece que los partidos políticos deben "dar la máxima publicidad a sus cartas orgánicas y programas de principios, en forma tal que el ciudadano pueda conocerlos ampliamente" ${ }^{38}$ La de Costa Rica, de 1949, alude a la publicidad en relación a las contribuciones privadas a los partidos políticos ${ }^{39}$, aunque también garantiza "el libre acceso a los departamentos administrativos con propósitos de información sobre asuntos de interés público", exceptuando los secretos de Estado. ${ }^{40}$

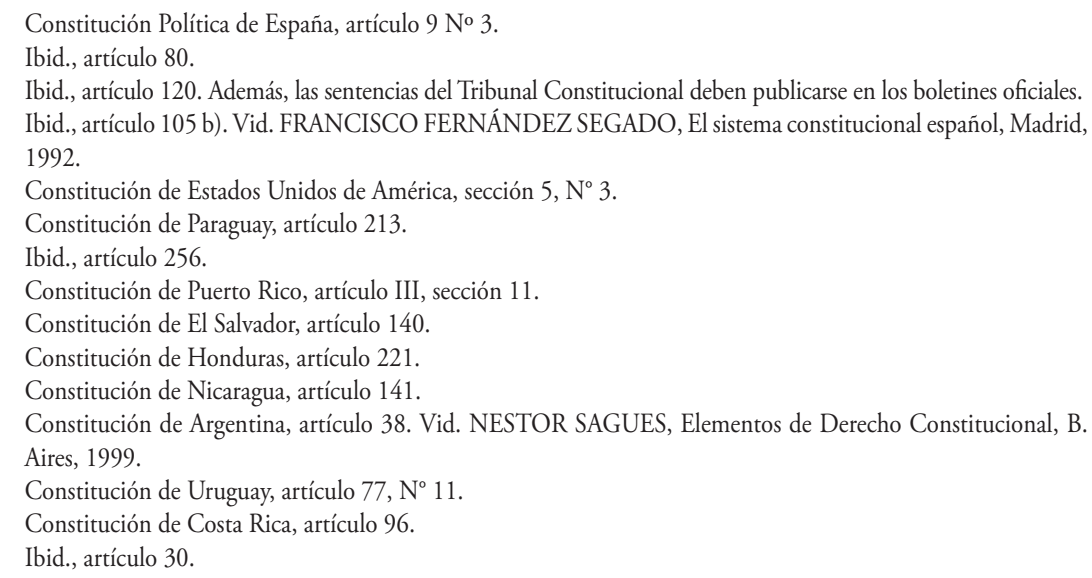


La reciente aprobada Constitución de República Dominicana alude a la transparencia y publicidad, dentro de los principios que deben orientar la actuación de la Administración Pública. ${ }^{41}$

La Carta Fundamental de Colombia, además de las referencias generales acerca de la publicidad de las sesiones de las Cámaras y de las leyes y actuaciones judiciales, consagra también el derecho de todas las personas a "acceder a los documentos públicos salvo los casos que establezca la ley". ${ }^{42}$

Cabe destacar que la Constitución mexicana incorporó expresamente una serie de principios y bases que deben regir el derecho de acceso a la información, conforme a los cuales:

"I. Toda la información en posesión de cualquier autoridad, entidad, órgano y organismo federal, estatal y municipal, es pública y sólo podrá ser reservada temporalmente por razones de interés público en los términos que fijen las leyes. En la interpretación de este derecho deberá prevalecer el principio de máxima publicidad.

II. La información que se refiere a la vida privada y los datos personales será protegida en los términos y con las excepciones que fijen las leyes.

III. Toda persona, sin necesidad de acreditar interés alguno o justificar su utilización, tendrá acceso gratuito a la información pública, a sus datos personales o a la rectificación de éstos.

IV. Se establecerán mecanismos de acceso a la información y procedimientos de revisión expeditos.

Estos procedimientos se sustanciarán ante órganos u organismos especializados e imparciales, y con autonomía operativa, de gestión y de decisión.

V. Los sujetos obligados deberán preservar sus documentos en archivos administrativos actualizados y publicarán a través de los medios electrónicos disponibles, la información completa y actualizada sobre sus indicadores de gestión y el ejercicio de los recursos públicos.

VI. Las leyes determinarán la manera en que los sujetos obligados deberán hacer pública la información relativa a los recursos públicos que entreguen a personas físicas o morales.

VII. La inobservancia a las disposiciones en materia de acceso a la información pública será sancionada en los términos que dispongan las leyes" ${ }^{43}$

Constitución de República Dominicana, artículo 138.

42 Constitución de Colombia, artículo 74. Vid. JACOBO PÉREZ ESCOBAR, Derecho Constitucional Colombiano, Bogotá, 2004.

43 Constitución Política de México, artículo 6. Vid. IGNACIO BURGOA, Derecho Constitucional Mexicano, México, 2009. 
La Constitución de Perú de 1993 consagra el derecho a "solicitar sin expresión de causa la información que requiera y a recibirla de cualquier entidad pública, en el plazo legal, con el costo que suponga el pedido. Se exceptúan las informaciones que afectan la intimidad personal y las que expresamente se excluyan por ley o por razones de seguridad nacional". ${ }^{4}$ Del mismo modo, se alude a la transparencia en relación al origen de los recursos económicos de los partidos políticos. ${ }^{45}$

La Ley Fundamental de Venezuela tutela el derecho a ser informado "por la Administración Pública, sobre el estado de las actuaciones en que estén directamente interesados $e$ interesadas, y a conocer las resoluciones definitivas que se adopten sobre el particular. Asimismo, tienen acceso a los archivos y registros administrativos, sin perjuicio de los limites aceptables dentro de una sociedad democrática en materias relativas a seguridad interior y exterior, a investigación criminal y a la intimidad de la vida privada, de conformidad con la ley que regule la materia de clasificación de documentos de contenido confidencial o secreto. No se permitirá censura alguna a los funcionarios públicos o funcionarias públicas que informen sobre asuntos bajo su responsabilidad" ${ }^{46}$

La Constitución ecuatoriana de 2008 consagra expresamente el derecho de las personas a "acceder libremente a la información generada en entidades públicas, o en las privadas que manejen fondos del Estado o realicen funciones públicas". A la vez que agrega que "no existirá reserva de información excepto en los casos expresamente establecidos en la ley. En caso de violación a los derechos humanos, ninguna entidad pública negará la información ${ }^{\text {'\$7 }}$. Para tal efecto, se prevé expresamente una acción de acceso a la información pública ${ }^{48}$, A la vez que se crea una Función de Transparencia y Control Social ${ }^{49}$.

La Constitución boliviana de 2009 consagra la publicidad y transparencia con motivo de la jurisdicción ${ }^{50}$, de la administración ${ }^{51}$ o de la política fiscal. ${ }^{52}$

Finalmente, cabe citar el caso de Panamá, en la que se consagra el acceso a las bases de datos o registros. ${ }^{53}$

\footnotetext{
Constitución Política de Perú, artículo 2 No 1.

Ibid., artículo 35.

Constitución de Venezuela, artículo 143.

Constitución de Ecuador, artículo $18 \mathrm{~N}^{\circ} 2$.

"Art. 91.- La acción de acceso a la información pública tendrá por objeto garantizar el acceso a ella cuando ha sido denegada expresa o tácitamente, o cuando la que se ha proporcionado no sea completa o fidedigna. Podrá ser interpuesta incluso si la negativa se sustenta en el carácter secreto, reservado, confidencial o cualquiera otra clasificación de la información. El carácter reservado de la información deberá ser declarado con anterioridad a la petición, por autoridad competente y de acuerdo con la ley.

49 "La Función de Transparencia y Control Social estará formada por el Consejo de Participación Ciudadana y Control Social, la Defensoría del Pueblo, la Contraloria General del Estado y las superintendencias. Estas entidades tendrán personalidad jurídica y autonomía administrativa, financiera, presupuestaria y organizativa" (artículo 204).

50 Constitución de Bolivia, artículo 180.

$51 \quad$ Ibid., artículo 232.

52 Ibid., artículo 323.

53 Constitución de Panamá, artículo 43.
} 


\section{El Derecho a Recibir Información y los Antecedentes Previos del Artículo Octavo}

Como se sabe, la Comisión de Ética Pública, en 1994, instó a legislar sobre acceso a la información. En tal sentido, se estimó conveniente incorporar en la Constitución Política de la República los principios de probidad funcionaria y de transparencia en la función pública.

Así, se consideró necesario que en el nuevo artículo octavo, además de incorporar el principio de probidad, "debiera expresarse que toda función pública se ejercerá con transparencia, de manera que se permita y promueva el conocimiento de los procedimientos, contenidos y fundamentos de las decisiones que se adopten en el ejercicio de ellas, sin perjuicio de las materias que, por razones de seguridad o de interés nacional, deban mantenerse en secreto". ${ }^{54}$

Del mismo modo, cabe recordar que a fines de los noventa se modifica la Ley de Bases de la Administración del Estado, incorporando expresamente el principio de transparencia en el ejercicio de la función pública, "de manera que permita y promueva el conocimiento de los procedimientos, contenidos y fundamentos de las decisiones que se adopten en ejercicio de ella". 55

De esta forma, como ha señalado el Tribunal Constitucional, "el derecho de acceso a la información pública surgió primeramente a nivel legal para ser posteriormente recogido, en los términos que se han reseñado, por la reforma constitucional de agosto de 2005, en el artículo $8^{\circ}$, inciso segundo, de la Carta Fundamental" ${ }^{56}$

De igual modo, debe destacarse la sentencia dictada por la Corte Interamericana, en el 2006, en el caso Marcel Claude Reyes y otros contra la República de Chile, en el que se resalta que "el valor del acceso a la información comprende la promoción de los objetivos más importantes en las Américas, incluida una democracia transparente y efectiva, respeto por los derechos humanos, la estabilidad de los mercados económicos y la justicia socioeconómica. Es ampliamente reconocido que, sin acceso público a la información en poder del Estado, los beneficios politicos que derivan de un clima de libre expresión no pueden realizarse plenamente. El acceso a la información promueve la rendición de cuentas y la transparencia dentro del Estado y permite un debate público sólido e informado. De esta manera el acceso a la información habilita a los ciudadanos para asumir un papel activo en el gobierno, que es condición de una democracia sana. Un mecanismo transparente que brinda acceso a información en poder del Estado es también esencial para fomentar un clima de respeto por todos los derechos humanos. El acceso a la información en poder del Estado

54 Informe de la Comisión Nacional de Ética Pública sobre probidad pública y la prevención de la corrupción, creada por Decreto No 423, publicado en el Diario Oficial el 18 de abril de 1994. Una década después se propusieron diversas medidas para fortalecer la transparencia.

55 Artículo 13 de la Ley de Bases Generales de la Administración del Estado, modificado por la Ley No 19.653.

56 TRIBUNAL CONSTITUCIONAL, Rol 634, consid. 11. 
es igualmente necesario para evitar futuros abusos de los funcionarios gubernamentales $y$ para asegurar la garantía de contar con recursos efectivos contra tales abusos" ${ }^{57}$.

Cabe sí señalar que en la misma decisión, la Comisión Interamericana, si bien destaca la nueva legislación dictada a fines de los noventa, la estima insuficiente por considerar que sólo se aplica a los actos administrativos y por la amplitud y vaguedad de las excepciones previstas. ${ }^{58}$

Ahora bien, el derecho a recibir la información forma parte de la libertad de expresión tutelada en el artículo 19 No 12 de la Constitución Política de la República. En efecto, tal como lo señalara el Tribunal Constitucional, la "historia y la doctrina constitucional en general permiten afirmar que estas libertades -se refiere a las de opinión e informacióncomprenden también el derecho a recibir informaciones" 59

El mismo Tribunal ha concluido que el derecho de acceso a la información pública se encuentra reconocido en la Carta Fundamental -aunque no en forma explícita- "como un mecanismo esencial para la vigencia plena del régimen democrático y de la indispensable asunción de responsabilidades unida a la consiguiente rendición de cuentas que éste supone por parte de los órganos del Estado hacia la ciudadanía". Al mismo tiempo, la publicidad de los actos de tales órganos, garantizada, entre otros mecanismos, por el derecho de acceso a la información pública, "constituye un soporte básico para el adecuado ejercicio y defensa de los derechos fundamentales de las personas que, eventualmente, puedan resultar lesionados como consecuencia de una actuación o de una omisión proveniente de los mismos". 60

\section{La Reforma Constitucional de 2005 y la Consagración de la Publicidad y Transparencia}

La reforma constitucional de 2005 consagra expresamente la publicidad, en el inciso segundo del artículo octavo ${ }^{61}$, al indicar que "son públicos los actos y resoluciones de los órganos del Estado, asi como sus fundamentos y los procedimientos que utilicen. Sin embargo, solo una ley de quórum calificado podrá establecer la reserva o secreto de aquéllos o de éstos,

\footnotetext{
Comisión Interamericana de Derechos Humanos, 8 de julio de 2005 cap. VII, No 48.

Ibid., cap. VII, No 90.

TRIBUNAL CONSTITUCIONAL, Rol 226, 30.10.1995, consid. 20.

TRIBUNAL CONSTITUCIONAL, Rol 634, 9.08.2007, consid.

La moción de los senadores de la Alianza por Chile (Boletín Nº 2526-07), que sirvió de base al texto aprobado, proponía: "Las actuaciones de los órganos del Estado y los documentos que obren en su poder son públicos, sin perjuicio de la reserva o secreto que se establezca con arreglo a la ley en casos en que la publicidad afecte el debido cumplimiento de las funciones de tales órganos, los derechos de las personas, la seguridad de la Nación o el interés nacional". Por su parte, la moción de los senadores de la Concertación (Boletín $\mathrm{N}^{\circ}$ 2534-07) expresaba que "toda función pública deberá desempeñarse de modo intachable, dando preeminencia al interés general sobre el particular, y de manera que permita y promueva el conocimiento de los procedimientos y fundamentos de las decisiones que se adopten en ejercicio de ella". En el debate producido en la Comisión del Senado se incorporaron no solo las "resoluciones" sino también los "actos" de la Administración.
} 
cuando la publicidad afectare el debido cumplimiento de las funciones de dichos órganos, los derechos de las personas, la seguridad de la Nación o el interés nacional".

Tal como se dejó constancia en la historia fidedigna de la reforma constitucional, la publicidad y la transparencia no son términos idénticos. ${ }^{62}$

Como ha señalado un autor, la publicidad "se configura más bien como una obligación de los órganos del Estado, ligada al imperativo de dar a conocer sus actos decisorios", mientras que la transparencia "se vincula a los procedimientos, contenidos y fundamentos de estos actos, tema que se asocia al derecho de las personas a ser informadas" ${ }^{63}$

Durante la tramitación de la reforma constitucional, se recordó por el profesor Rolando Pantoja que la publicidad se "entiende que es una norma implícita dentro de la Carta Fundamental. El hecho de que Chile sea una República democrática implica que las autoridades públicas responden a la sociedad; por lo tanto tiene a disposición de los ciudadanos los actos $y$ da cuenta de ellos" ${ }^{64}$

Efectivamente es posible sostener que la publicidad de las actuaciones de los gobernantes se encuentra íntimamente vinculado con el régimen republicano y democrático que establece nuestro artículo octavo. Por lo mismo, como lo recuerda Bobbio uno de los principios fundamentales del Estado Constitucional Democrático es que "la publicidad es la regla; el secreto la excepción" ${ }^{5}$

Adicionalmente, debe tenerse presente que la Carta Fundamental asegura, en su artículo 19 No 14 , el derecho de petición, conforme al cual se pueden presentar peticiones a la autoridad sobre cualquier asunto de interés público o privado, sin otra limitación que la de proceder en términos respetuosos y convenientes.

62 El profesor Rolando Pantoja hace presente que "en general la publicidad se entiende como el hecho de notificar o publicar un acto, pero el sentido que le asigna la Ley sobre Probidad Administrativa fue más bien el de dar a conocer y tener siempre a disposición de los ciudadanos los actos de la administración. La publicidad, entonces, está estrictamente ligada a los actos de la Administración, en tanto que la transparencia está vinculada a los procedimientos, contenidos y fundamentos de estos actos". Por su lado, el profesor Humberto Nogueira indicó que el principio de transparencia "dice relación con el conocimiento de algo, que no es lo mismo que la publicidad. Desde este punto de vista, la publicidad se vincula más bien con la obligación del órgano que desarrolla la función de entregar al público los temas que son de relevancia pública. En cambio, la transparencia implica que la ciudadanía tiene derecho a reclamar esa información para que la actuación del órgano sea efectivamente legitimada desde el punto de vista de lo que es una sociedad democrática". (En PFEFFER U. EMILIO, Reformas Constitucionales 2005, Ed. Jurídica de Chile, 2005, p. 29 y 30). En el mismo sentido, el Senador Larraín hizo presente que la publicidad "consiste en dar a conocer los contenidos y fundamentos de las decisiones que se adoptan", mientras que la transparencia "significa que las personas puedan acceder a la información" (En SENADO DE LA REPÚBLICA, Reformas constitucionales 2005, historia y tramitación, 2006, p. 49).

63 HERNÁNDEZ E. DOMINGO, Notas sobre algunos aspectos de la reforma a las bases de la institucionalidad, en la reforma constitucional de 2005: regionalización, probidad y publicidad de actos”, en La Constitución Reformada de 2005, Ed. Humberto Nogueira A., 2005, p. 33)

64 PFEFFER U. EMILIO, Reformas Constitucionales 2005, Ed. Jurídica de Chile, 2005, p. 29.

65 NORBERTO BOBBIO, El Futuro de la Democracia. 
Por último, no debe olvidarse que las excepciones sólo pueden establecerse por ley de quórum ${ }^{66}$ y que éstas deben interpretarse restrictivamente ${ }^{67}$.

En tal sentido, el Tribunal Constitucional ha señalado que al referirse a los derechos de las personas, dicha expresión "está siendo utilizada en el mismo sentido amplio que en el artículo $1^{\circ}$, inciso cuarto, de la Carta Fundamental, comprendiendo tanto la protección de derechos subjetivos o derechos en sentido estricto cuanto de intereses legitimos" ${ }^{68}$ Concluyendo que una disposición que permite que el jefe superior del órgano requerido deniegue, por resolución fundada, la entrega de determinada información que se le solicita, en base a una supuesta "afectación sensible de intereses de terceras personas", no resulta compatible con el artículo $8^{\circ}$, inciso segundo, de la Constitución. En efecto, y como se recordó, desde la vigencia de la Ley $N^{o} 20.050$ solo corresponde a una ley de quórum calificado la determinación del contenido y alcance de las causales de secreto o reserva previstas en la Carta Fundamental. Así, la autoridad administrativa debe sujetarse a los parámetros fijados por aquélla a la hora de denegar la entrega de documentación pública que le haya sido solicitada, por estar afecta a secreto o reserva". 69

En cumplimiento del mandato constitucional se dictó la Ley No 20.285, sobre acceso a la información pública, y que fuera publicada en el Diario Oficial con fecha 20 de agosto de $2008 .^{70}$

De acuerdo a la misma, en virtud del principio de transparencia de la función pública, "los actos y resoluciones de los órganos de la Administración del Estado, sus fundamentos, los

66 Este punto fue resaltado por la Diputada señora Guzmán, enfatizando que "los problemas que actualmente genera la aplicación de la ley de probidad en lo que concierne a la transparencia de los actos de Gobierno se deben a que cada servicio, incluso mediante un reglamento, puede decretar el secreto y la confidencialidad de los actos propios de sus funciones. Eso, obviamente, lleva a que nada sea transparente" (En SENADO DE LA REPÚBLICA, Reformas constitucionales 2005, historia y tramitación, 2006, p. 60). Como señala un autor "debe descartarse, desde luego, toda alternativa de restringir el principio por medio de actos reglamentarios o, incluso, a través de decretos con fuerza de ley". HERNÁNDEZ E. DOMINGO, "Notas sobre algunos aspectos de la reforma a las bases de la institucionalidad, en la reforma constitucional de 2005: regionalización, probidad y publicidad de actos”, en La Constitución Reformada de 2005, Ed. Humberto Nogueira A., 2005, p. 36). Otro autor, en el mismo sentido, sostiene que "es inconstitucional-y siempre lo ha sido-declarar la reserva o secreto de los actos estatales, los documentos $y$ antecedentes en que se fundan o de los procedimientos de los cuales son su resultado, mediante disposiciones infralegislativas". Por lo mismo, se habría producido la "derogación de todos los preceptos reglamentarios que, en la actualidad, declaran confidencialidad de actos del Estado, así como las disposiciones legales que remiten o reenvían el ejercicio de esa potestad a los reglamentos o a disposiciones, incluso de inferior jerarquía que éstos"(FERNÁNDEZ G. MIGUEL A., "El principio de publicidad de los actos estatales en el nuevo artículo 8, inciso $2^{\circ}$, de la Constitución", en Reforma Constitucional, Ed. Francisco Zúńiga, 2005, p. 200 y 205). Con matices, por último, se ha afirmado que el texto constitucional vigoriza la publicidad "al elevarla a rango constitucional como regla general, definiendo los objetivos que autorizan su restricción y entregando a un legislador especial-de quórum calificado-el desarrollo de estos casos de excepción, minimizando la potestad reglamentaria" (RAMÍREZ A. JOSÉ A., Principio de probidad y transparencia en el ejercicio de las funciones públicas: alcances de la nueva Constitución de 2005, en Reforma Constitucional, Ed. Francisco Zúńiga, 2005, p. 244).

${ }_{67}$ En tal sentido, el Senador Larraín señaló que las excepciones "deben interpretarse en sentido estricto, como toda excepción en el ámbito legal” (En SENADO DE LA REPÚBLICA, Reformas constitucionales 2005, historia y tramitación, 2006, p. 55).

68 TRIBUNAL CONSTITUCIONAL Rol 634, consid. 23.

69) Ibid., consid. 28.

70 El Reglamento de la misma se contiene en el Decreto No 13, publicado en el diario Oficial de 13 de abril de 2009. 
documentos que le sirven de sustento o complemento directo y esencial, y los procedimientos que se utilicen para su dictación son públicos, salvo las excepciones que establece esta ley y las previstas en otras leyes de quórum calificado". A1 Asimismo es pública "la información elaborada con presupuesto público y toda otra información que obre en poder de los órganos de la Administración, cualquiera sea su formato, soporte, fecha de creación, origen, clasifcación o procesamiento, a menos que esté sujeta a las excepciones señaladas". ${ }^{72}$

Para efectos de lo anterior, se regulan los antecedentes actualizados que deben mantenerse a disposición del público en los sitios electrónicos por parte de los órganos de la administración, principio conocido como "transparencia activa" ${ }^{73}$ Del mismo modo, se regula el derecho de acceso a la información de los órganos de la Administración del Estado, específicamente los principios que lo informan ${ }^{74}$, el procedimiento ante la autoridad, el amparo ante el Consejo de Transparencia y el reclamo de legalidad ante la Corte de Apelaciones. ${ }^{75}$ Obviamente también se contiene la normativa que regula el régimen jurídico del Consejo para la Transparencia, corporación autónoma de derecho público. ${ }^{76}$

\section{Sentencia del Tribunal Constitucional y Nuevo Contencioso}

Al Tribunal Constitucional le correspondió revisar la constitucionalidad de algunas disposiciones de la Ley No 20.285. ${ }^{77}$ Especialmente en relación a leyes orgánicas constitucionales de ciertas instituciones.

Así, por ejemplo, debe destacarse que dicho tribunal dejó expresamente a salvo el control amplio de legalidad que le corresponde a la Contraloría General de la República. ${ }^{78}$ Del mismo modo, señaló que no le resulta aplicable a dicho órgano el reclamo ante el Consejo de Transparencia ${ }^{79}$ y por lo mismo no son vinculantes las normas generales que dicte dicho consejo. ${ }^{80}$

Artículo 5, inciso $1^{\circ}$ de la Ley No 20.285 .

Artículo 5, inciso 2 de la Ley No 20.285.

Título III de la Ley No 20.285 .

74 Particularmente los principios de relevancia, libertad de información, apertura o transparencia, máxima divulgación, divisibilidad, facilitación, no discriminación, oportunidad, control, responsabilidad y gratuidad (artículo 11).

75 Título IV de la Ley No 20.285.

76 Título V de la Ley No 20.285. Sobre el primer año de labor de dicho órgano vid. ENRIQUE RAJEVIC M., La jurisprudencia inicial del Consejo para la Transparencia, Revista de Derecho del Consejo de Defensa del Estado, 2009, p. 31 y ss.

77 TRIBUNAL CONSTITUCIONAL, Rol No 1051.

78 Ibid., consid. 34.

79 Ibid., consid. 37.

$80 \quad$ Ibid., consid. 38. 
En relación al Banco Central, como órgano autónomo, se declara que tampoco le resulta aplicable el artículo octavo en cuanto establece un reclamo ante el referido Consejo para la Transparencia. ${ }^{81}$

Idéntico razonamiento se efectúa respecto de Ministerio Público ${ }^{82}$, el Tribunal Constitucional y el Tribunal Calificador de Elecciones, "por cuanto la autonomía que la Constitución ha asignado a ciertos órganos del Estado, como los recién mencionados, y que se proyecta en una triple dimensión-organizativa, institucional y normativa-implica, precisamente, que cada uno de estos ámbitos de acción no puede estar supeditado, en su ejercicio, a órganos que se relacionen, aunque sea en forma indirecta, con las labores de gobierno y administración propias de la función ejecutiva". ${ }^{33}$ Por lo mismo, tampoco resultan aplicables a dichos órganos las normas generales que dicte el Consejo para la Transparencia. ${ }^{84}$

Adicionalmente se establece que no resulta procedente el reclamo de legalidad respecto del Tribunal Constitucional y de los tribunales electorales, "toda vez que dichos órganos jurisdiccionales especializados se rigen por sus propios estatutos constitucionales, contenidos en los capitulos VIII y IX de la Constitución, respectivamente, por lo cual, de acuerdo a lo previsto en el artículo 82 de la Carta Fundamental, están al margen de la superintendencia directiva, correccional y económica de la Corte Suprema". Por consiguiente, "no resultaría constitucionalmente admisible que sus resoluciones o determinaciones queden sujetas al escrutinio de un tribunal ordinario de justicia, subalterno de la Corte Suprema, como es una Corte de Apelaciones". Por lo demás, se concluye, "el debido acatamiento de ellos al principio de publicidad y transparencia consagrado en el artículo $8^{\circ}$ de la Constitución se satisface adecuadamente con la divulgación de sus resoluciones jurisdiccionales y de otros antecedentes relevantes de su quehacer, en los términos que contempla el artículo $7^{\circ}$ de la Ley de Transparencia de la Función Pública y de Acceso a la Información de la Administración del Estado, que el mismo ARTÍCULO NOVENO del proyecto en examen hace aplicable a esos órganos". 5

Debe destacarse una sentencia dictada por el Tribunal Constitucional en la que se declaró la inconstitucionalidad de un Auto Acordado dictado por la Corte de Apelaciones de Santiago, que regulaba el procedimiento disciplinario, que se estimó infringía la garantía de publicidad prevista en el artículo octavo constitucional. ${ }^{86}$

${ }^{81}$ Ibid., consid. 41. Cabe tener presente que se declaró inconstitucional la normativa que obligaba al Banco Central a "adoptar" las normas generales que dicte el Consejo para la Transparencia, al estimar que dichos términos imperativos afectaban su autonomía constitucional (consid. 54).

82 La Corte Suprema, en reciente queja, acogida, ha señalado que respecto del Ministerio Público debe reclamarse directamente ante la Corte de apelaciones respectiva (Rol No 6787-2010, 6 de diciembre de 2010).

Ibid., consid. 44.

Ibid., consid. 48 .

Ibid., consid. 46.

86 En tal sentido, se cuestiona el carácter reservado de la investigación sumarial, concluyendo que "la contradicción de la norma impugnada con la Carta Fundamental se hace evidente con el solo contraste de la literalidad de ambos preceptos, pues mientras el de rango inferior, la letra d) del número $4^{\circ}$ del Auto Acordado establece una reserva absoluta del sumario administrativo - el que se compone de actuaciones y resoluciones de un órgano del Estado-, reserva que alcanza incluso al funcionario sujeto a investigación, el precepto de mayor jerarquía, contenido en el artículo $8^{\circ}$ de la 
Finalmente, resulta interesante analizar algunos pronunciamientos que ya han ido efectuando las Cortes de Apelaciones, tanto desde el punto de vista formal como de fondo.

Así, por ejemplo, en cuanto a aspectos procedimentales se ha señalado que la reclamación no solo procede respecto de la resolución que deniega el acceso a la información. ${ }^{87} \mathrm{La}$ Corte Suprema, a su turno, ha estimado improcedente el recurso de apelación respecto de sentencias interlocutorias dictadas por la Corte de Apelaciones conociendo del reclamo. ${ }^{88}$ De igual manera, existen pronunciamientos acerca de la extemporaneidad de la presentación. ${ }^{89}$

En cuanto al fondo, se han revocado decisiones del Consejo para la Transparencia respecto de la información sobre procesos de selección realizados por la Dirección Nacional del Servicio Civil. ${ }^{90}$

Además, se ha determinado que deben excluirse actas de directorio de una fundación, limitándose la entrega de antecedentes a la memoria y balances de dicho ente, modificándose en parte lo resuelto en sede de amparo. ${ }^{91}$

A su vez, se han confirmado decisiones referidas a la información y antecedentes que debe entregar una universidad estata ${ }^{92}$, la obligación de un municipio de otorgar información educacional ${ }^{93}$ como a su vez la individualización de actuarios de un sumario ${ }^{94}$ o la información que debe contenerse en un sitio electrónico ${ }^{95}$.

Del mismo modo, se ha sentenciado que debe entregarse ciertos informes en procesos de postulación realizados por el Servicio de Impuestos Internos ${ }^{96}$, la documentación que dispone la Subsecretaría de Minería respecto de un paso fronterizo de un proyecto minero ${ }^{97}$, el sumario administrativo efectuado por la $\mathrm{PDI}^{98}$, la información sobre sustancias tóxicas de que dispone la Subsecretaría de Salud ${ }^{99}$ y la individualización de las personas que desempeñan la función de capellanes en el Ejército ${ }^{100}$.

Carta Fundamental, dispone la publicidad de los procedimientos y resoluciones de los órganos del Estado, salvo que el secreto sea dispuesto por una ley de quórum calificado, fundada en las razones que la propia Constitución establece, lo que no ocurre en la especie" (Rol 783, consid. 17).

ICA de SANTIAGO, Rol 943-2010. En el mismo sentido, Rol 2080-2010.

C. SUPREMA, Rol 5799-2010, 29 de octubre de 2010.

ICA de SANTIAGO, Rol 4625-2009, 23 de octubre de 2009.

90 ICA de SANTIAGO, Rol 943-2010, 3 de septiembre de 2010. Una decisión diversa en Rol 2080-2010, 22 de noviembre de 2010, donde se obliga a entregar la información.

ICA de SANTIAGO, Rol 950-2010, 7 de octubre de 2010.

ICA de SANTIAGO, Rol 1803-2010, $1^{\circ}$ de octubre de 2010.

ICA de VALPARAISO, Rol 294-2010, 29 de junio de 2010. En el mismo sentido, ICA de SANTIAGO, respecto de los antecedentes de concurso público para docente en una corporación municipal, Rol 8131-2009, 10 de agosto de 2010.

94 ICA de SANTIAGO, Rol 2335-2010, 1 de diciembre de 2010.

ICA de VALPARAÍSO, Rol 2361-2009, 14 de junio de 2010.

ICA de SANTIAGO, Rol 8067-2009, 25 de mayo de 2010.

ICA de SANTIAGO, Rol 8405-2009, 4 de octubre de 2010.

ICA de SANTIAGO, Rol 2267-2010, 25 de octubre de 2010.

ICA de SANTIAGO, Rol 1103-2010, 6 de diciembre de 2010.

100 ICA de SANTIAGO; Rol 2275-2010, 23 de noviembre de 2010. 


\section{Reflexiones Finales}

Junto con las leyes son importantes también las buenas costumbres. Como afirmara la Carta de 1822, "la felicidad general se cifra en la observancia de las leyes y éstas son vanas sin costumbres y espiritu público". ${ }^{101}$ La publicidad de las actuaciones ha adquirido tal importancia que un autor la ha calificado como la tercera regla de oro del derecho público, después de la separación de poderes y el principio de juridicidad. ${ }^{102}$

Sin embargo, el principio es nuevo de puro viejo. Tanto que para algunos ya se puede encontrar en Kant, quien sostuviera que "sin publicidad no habría justicia, pues la justicia no se concibe oculta, sino públicamente manifiesta; ni habría por tanto derecho, que es lo que la justicie distribuye y define. La capacidad de publicarse debe, pues, residir en toda pretensión de derecho". De modo que la fórmula trascendental del derecho público sería: "las acciones referentes al derecho de otros hombres son injustas, si su máxima no admite publicidad". ${ }^{103}$ Lo cierto es que ya en el evangelista San Juan -hace dos mil ańos- se encuentra una referencia a la publicidad y transparencia, puesto que "el que obra mal odia la luz y no se acerca a ella, por temor de que sus obras sean descubiertas". ${ }^{104}$

En todo caso ya algunos sostienen que los antecedentes remotos normativos se encuentran en la legislación sueca de 1766 que otorga acceso a las actas públicas, aparentemente inspirada en la cultura oriental. ${ }^{105}$

De este modo, la publicidad y transparencia son valores fundamentales en un Estado Democrático, aunque obviamente ello no deba llevarse a extremos absurdos como hemos visto estos días en relación a la información contenida en un sitio electrónico respecto de las relaciones internacionales de una potencia mundial, lo que ha motivado una controversia universal. ${ }^{106}$

Por último: la motivación constituye ahora también un principio fundamental reconocido a nivel constitucional. ${ }^{107}$ De esta forma, todo acto emanado de un órgano del Estado, debe ser fundado. Se trata, por lo demás, como recordara sabiamente don Andrés Bello, de una "práctica tan conforme al principio de responsabilidad general, que es el alma del gobierno republicano, o mejor decir, de todo gobierno". ${ }^{108} \mathrm{Y}$ es que, como afirmara Unamuno, antes que vencer hay que convencer.

\footnotetext{
Constitución de 1822, Parte Preliminar.

102 CEA E. JOSÉ LUIS, Tercera regla de oro del Derecho Público, en Estado Social y Justicia Constitucional, Cuadernos del TC No 41 (2009), p. 41 y ss.

103 MANUEL KANT, Lo bello y lo sublime. La paz perpetua, Buenos Aires, 1957, p. 150. Citado en CEA E., ob. cit., p. 46.

104 SAN JUAN, 3, 14-21.

105 ACKERMAN JOHN M. y SANDOVAL IRMA E., Leyes de acceso a la información en el mundo, México, 2005.

106 Wikileaks.

107 Así lo ha señalado el Tribunal Constitucional respecto de las sentencias judiciales (Rol 1373, 22 de junio de 2020).

108 Necesidad de fundar las sentencias, artículo publicado en El Araucano, 1834; en Andrés Bello, Escritos jurídicos, políticos y universitarios, Edeval, 1979, selección de A. Squella, p. 112.
} 